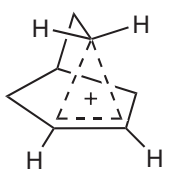

or

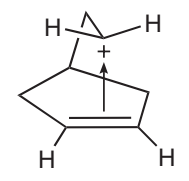

Non-classical
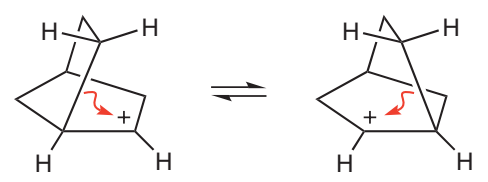

Classical

chemists from Germany and the USA have determined the low-temperature crystal structure of the norbornyl cation.

In 1949, Saul Winstein suggested that the cationic intermediate existed as a single entity with the charge spread across three carbon atoms - a three-centre-two-electron bond. Herbert Brown, however, countered that there was no convincing evidence that couldn't be explained by the more classical depiction of two carbocations that were in rapid equilibrium (Winstein and Brown's different suggestions for the structure of the norbornyl cation are shown). In the years between the first preparation of a stable form of the norbornyl cation and now, a variety of analytical techniques - in particular a variety of specialized NMR spectroscopy experiments - have been applied to try and resolve this cationic conundrum. And despite the fact that many of these experiments support the formation of a nonclassical ion, neither do they rule out Brown's point of view.

Now, Ingo Krossing, Karsten Meyer and co-workers have obtained crystals of the norbornyl cation suitable for X-ray diffraction analysis. The team's interest in the binding of cations to weakly coordinating anions led them to use a soft bromoaluminate $\left(\mathrm{Al}_{2} \mathrm{Br}_{7}^{-}\right)$counterion to isolate the norbornyl cation salt. Obtaining a crystal structure was not without difficulty; even at $86 \mathrm{~K}$, the structure of the cation in the crystal was disordered - a fact ascribed to the nearly spherical shape of the ion. Lowertemperature measurements eventually solved this problem, and the non-classical structure was confirmed - but only after a slow and careful cooling and annealing procedure was developed for the crystals. The $\mathrm{C}-\mathrm{C}$ bond distances determined from the crystals support the non-classical ion picture with equal bond lengths $(\sim 1.8 \AA)$ for the bridging bonds - exceeding the usual single bond value - and a partial double-bond at the base $(\sim 1.4 \AA)$.

\section{COPOLYMER NETWORKS}

\section{Malleable matter}

Proc. Natl Acad. Sci. USA 110, 12555-12559 (2013)

Shape-memory materials can be deformed by an external stimulus and then returned to their original shape under certain conditions. Typically, a material is heated above a transition temperature - where it can be deformed through physical strain and when cooled down the material adopts a different shape. Heating the material above the transition temperature again relaxes the strain and the material returns to its original shape. A better scenario, however, would be where a material can 'remember' two forms - a high-temperature and a lowtemperature one - and reversibly alternate between them under repeated heating/ cooling cycles.

A German-based research team led by Andreas Lendlein has now devised polymeric actuators that can first be bent into a chosen shape and then repeatedly switched between an expanded and a contracted form through heating and cooling cycles - with a tunable temperature range. Lendlein and co-workers had previously prepared reversible shapememory materials that can alternate between two shapes, by combining in a copolymer network two polymeric segments that crystallize at different temperatures. One polymer acts as a 'skeleton': it is brought to an amorphous state on heating and when cooled down under physical strain it crystallizes and imposes a particular shape on the material. This skeleton is retained throughout the temperature range at which the other polymer - responsible for actuation either crystallizes (on cooling) or loses crystallinity (on heating). The reversible crystallization and decrystallization of this 'actuation domain' causes macroscopic changes in the material, which alternates between two morphologies.

In the current study, the skeleton and the actuation domain have the same chemical composition - a covalently crosslinked copolymer poly[ethylene-co(vinyl acetate)]. The network crystallizes over a broad temperature range $\left(25-90^{\circ} \mathrm{C}\right)$, so that part of the material serves as the skeleton and the remaining part acts as the actuation domain. Repeated cooling and heating (below $90^{\circ} \mathrm{C}$ ) causes the chosen shape to contract and expand. Heating the copolymer network over $90^{\circ} \mathrm{C}$ erases the shape memory and the same process can be carried out with a new shape imposed through cooling under strain.

Written by Stephen Davey, Ruth Doherty,

Russell Johnson and Anne Pichon.

\section{blog $_{\text {roll }}$ i}

\section{Everyday chemistry}

A closer look at the chemistry all around us and advice on countering chemophobia.

Social media is often cast as an endless source of procrastination and a drain on productivity. However, critics typically overlook the advantages of online interactions, such as the potential to foster exciting international collaborations! Renée Webster of Lost in Scientia (http:// go.nature.com/IFDZcl) recently teamed up with Vittorio Saggiomo of Labsolutely (http://go.nature.com/1NSxH6) to resolve a long-standing and controversial scientific question: what is actually in Marmite?

Combining solid-phase microextraction, GC-MS, NMR spectroscopy and visual microscopy, Webster and Saggiomo probed the composition and properties of this intractable mixture. They take the reader through the use of these techniques in an entertaining and informative fashion. With these preliminary studies complete, perhaps future work can offer some insight into the love/hate relationship people tend to have with Marmite.

Meanwhile at the University of Bristol, Jenny Slaughter and Natalie Fey have started a new blog, Picture It (http://go.nature. com/UiBewx). With beautiful photography, lucid prose and a healthy dose of organic synthesis they bring everyday chemistry to life. Their first posts take a closer look at plants, starting with roses and rhubarb.

Finally, on a more serious note, at In the Pipeline Derek Lowe (http://go.nature.com/ $16 \mathrm{gKzb}$ ) issues a thorough takedown of chemical scare-mongering, and reignites the debate on tackling bad science in the media. In response, Ash Jogalekar of The Curious Wavefunction (http://go.nature.com/ HeaYFE) calls for chemists to unite and lobby on a national scale to oppose chemical myths and misconceptions. Whether we engage on a personal or political level, Janet Stemwedel of Doing Good Science (http:// go.nature.com/MHpm7Z) reminds us to do so intelligently, sympathetically and without using simplistic science models of communication.

Written by Andrew Bissette, who blogs at http://behindnmrlines.blogspot.co.uk/ 